\title{
Higher Risk of Light-Induced Retinal Damage Due to Increase of Intraocular Irradiance by Endoillumination
}

\author{
Philipp S. Koelbl (D) - Martin Hessling • Christian Lingenfelder • \\ Sebastian Kupferschmid
}

Received: November 2, 2018 / Published online: December 17, 2018

(C) The Author(s) 2018

\begin{abstract}
Introduction: All applied illumination systems are validated according to a standard that measures in an experimental setup the direct radiation intensity on a surface in an aqueous solution, not involving an eyeball. Due to various factors, multiple intraocular light-tissue interactions could occur and lead to retinal irradiation intensities that are higher than the irradiation caused by direct illumination. The aim of this work is to investigate the hypothesis that intraocular and technical reference irradiance is different.
\end{abstract}

Enhanced digital features To view enhanced digital features for this article, go to https://doi.org/10.6084/ m9.figshare.7411403.

P. S. Koelbl $(\bowtie) \cdot$ M. Hessling

Institute of Medical Engineering and Mechatronics, Ulm University of Applied Sciences, Albert-EinsteinAllee 55, 89081 Ulm, Germany

e-mail: philippkoelbl@gmx.de

P. S. Koelbl

Medical Faculty, Ulm University, Albert-Einstein-

Allee 7, 89081 Ulm, Germany

C. Lingenfelder

Pharmpur GmbH, Messerschmittring 33, 86343

Konigsbrunn, Germany

S. Kupferschmid

Clinic of Ophthalmology, Bundeswehrkrankenhaus

Ulm, Oberer Eselsberg 40, 89081 Ulm, Germany
Methods: Using an illumination system and a calibrated optical fiber, the irradiance in porcine eyes was measured at the posterior pole (macula) and compared with reference measurements. We compared two endoilluminators (spotlight and wide-angle) at a total of nine porcine eyes with a brown iris and five porcine eyes with a blue iris.

Results: The intraocular irradiance was always significantly higher compared to reference measurements $(p<0.001)$. Between eyes with a blue or brown iris, no significant difference was observed.

Conclusion: A significantly higher irradiance could be measured compared to a reference measurement with the same illumination setup. The intraocular illumination increased between 30 and $60 \%$, dependent on the distance of the distal end of the light fiber (4-12-mm distance to the retina). This leads to the assumption that the so far allowed "safe" exposure times for illumination systems are overestimated and the potential hazard to the retina is higher.

Keywords: Endoillumination; Intraocular illumination; Light hazard; Light-induced retinal damage; Light toxicity; Pars plana vitrectomy 


\section{INTRODUCTION}

Modern pars plana vitrectomy would be inconceivable without sufficiently bright illumination of the vitreous cavity. However, it is well known that the visible radiation poses a very high risk to the retina [1-14]. Especially, light with a wavelength below $500 \mathrm{~nm}$ $[2,10,15,16]$ has a particularly high potential to damage the photoreceptors and the retinal pigment epithelium (RPE) [14, 17]. White light usually has a high proportion of this wavelength range, so daylight at midday $[4,18]$, for example, can cause visible damage to the retina within just a few minutes. Experiments with rhesus monkeys using the illumination of an ophthalmoscope have already shown damage to the photoreceptors and changes to the RPE after 15 min [18]. Frequent investigations with lightemitting diode (LED) lighting systems have shown a particularly high risk potential at wavelengths below $500 \mathrm{~nm} \mathrm{[19-21].} \mathrm{Xenon}$ lamps with a comparable irradiance also have a high risk potential [22].

To keep the generated oxidative stress in the retina at a safe level, it is important to determine the total radiant exposure $H_{\mathrm{e}}$ with insurable and imputed hazard. Studies on retinal damage mostly performed using in vivo models $[18,23]$ revealed that with blue light, e.g. at a total radiant exposure of $20 \mathrm{~J} / \mathrm{cm}^{2}$ [23], irreversible damage can occur. A standard for determining intraocular illumination sets $10 \mathrm{~J} /$ $\mathrm{cm}^{2}$ as a guide value not to be exceeded [10, 24].

However, when the power of lighting systems is determined, no attention is paid to the anatomical structure of the eye, which has a very special optical geometry similar to a sphere $[25,26]$.

Following the guidelines, the irradiance of an illumination system is measured in aqueous solution at a defined distance to a detector surface $[10,24]$. Inside a sphere, however, an electromagnetic wave (light) can be reflected several times. Therefore, it is possible that a defined area is not only irradiated by direct light but also by indirect lights through multiple intraocular light-tissue interactions. As a result, the incident radiant exposure could increase and a safe guide value would be reached more quickly. Measuring the intensity outside the eye, e.g. during an approval procedure, might result in lower irradiation values, compared to the actual intraocular irradiation and therefore pose an unintended higher risk to the retina during medical treatment.

This hypothesis will be examined in the following in ex vivo porcine eyes.

\section{METHODS}

\section{Illumination System}

Employed was the light source of the Accurus Surgical System version 600 DS from Alcon Laboratories Inc. (Fort Worth, TX, USA) with a halogen lamp. For intraocular illumination, two different endoilluminators were utilized to investigate different angular radiation profiles. A hand-held 23G wide-field endoilluminator from Geuder (GH; Fig. 1a, b) and a $23 \mathrm{G}$ spotlight endoilluminator from Alcon $(\mathrm{AH}$; Fig. 1c, d) were adduced. Both were implemented using a 23G trocar from Alcon.

For the irradiance on a defined surface, the radiation angle of the emitter is relevant. Since this angle can change during the transition between two optical media (Snell's law), it is important to measure in a medium that has the same refractive index as in the later application. Here the measurements were performed in $0.9 \%$ $\mathrm{NaCl}$ solution $(n=1.33)$.

\section{Specimen Material}

For intraocular measurements, porcine eyes of a local slaughterhouse were adduced. Five eyes with a blue iris and nine eyes with a brown iris were selected to investigate potential differences between levels of pigmentation. The measurements were taken on the day of the enucleation. The porcine eye model was chosen because healthy human fresh enucleated eyes were not available due to ethical guidelines. Porcine eyes are an approved model in ophthalmic research [27] because the anatomical composition is very similar to that of humans. 

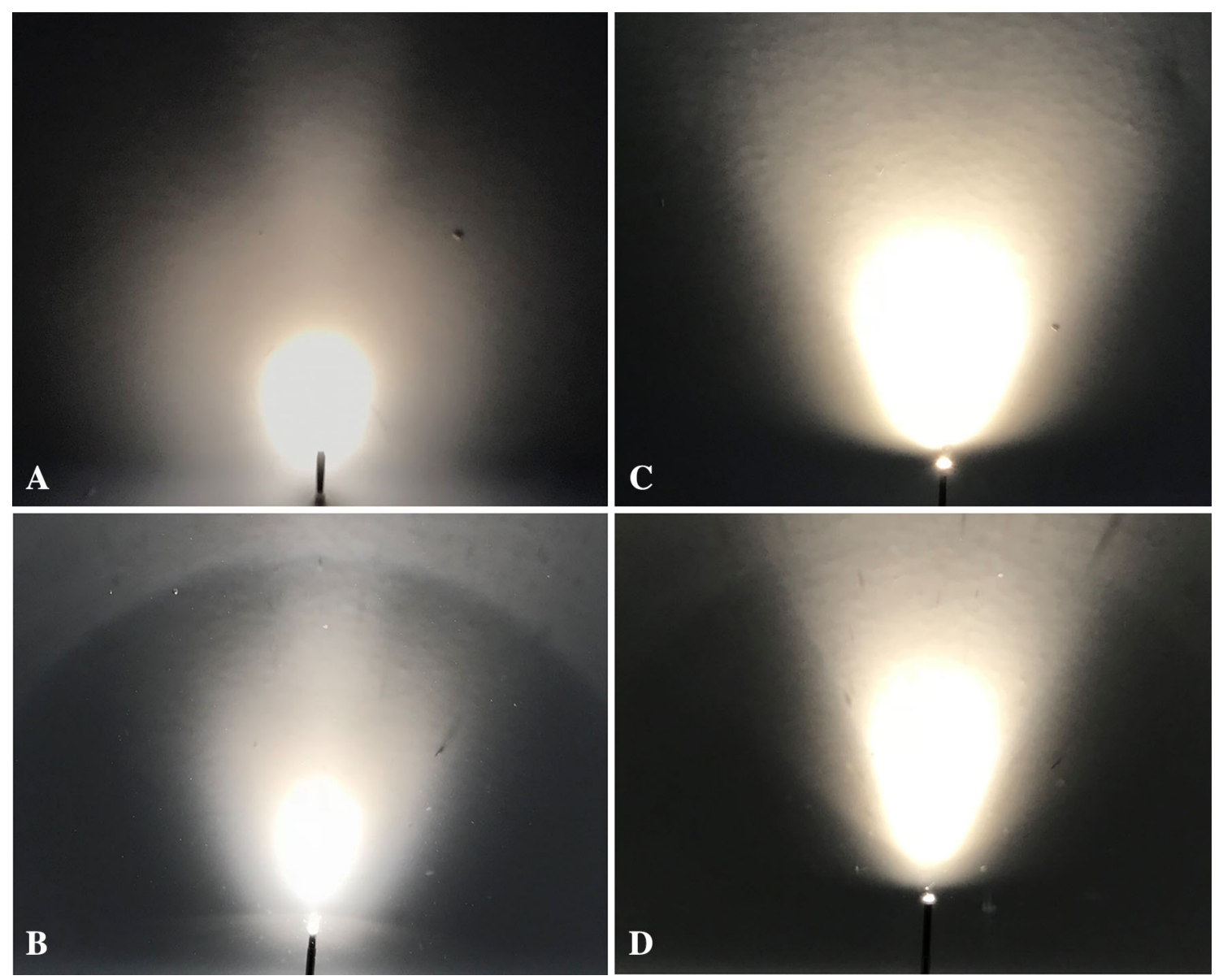

Fig. 1 Endoilluminators with two different angular distribution profiles in air $(n=1.0)$ and $0.9 \% \mathrm{NaCl}$ solution ( $n=1.33$ ). In a (air) and $\mathbf{b}$ (water), a handheld $23 \mathrm{G}$ wideangle endoilluminator from Geuder $(\mathrm{GH})$ is illustrated. In

All institutional and national guidelines for the care and use of laboratory animals were followed.

\section{Measurement Setup}

An optical fiber with diffuser tip (Thorlabs, CFDSB20, NA $=0.37$ ) was used to measure the intraocular irradiance. This fiber was selected for its feature to detect light from every angle in the range of $\pm 90^{\circ}$ almost equally. The normalized angle profile for white light branches between $0^{\circ}$ and $90^{\circ}$ with a minimum detection of $70 \%$ (Fig. 2).

To determine the irradiance $E_{\mathrm{e}}$ by a fiber, it was calibrated using an appropriate lamp. The

c (air) and d $(0.9 \% \mathrm{NaCl}$ solution), a $23 \mathrm{G}$ spotlight endoilluminator from Alcon $(\mathrm{AH})$ is imaged. The radiation angles are smaller in water

emission spectrum was measured by the spectrometer SensLine AvaSpec 2048 XL of Avantes BV (The Netherlands), using the software AvaSoft 8.4. The fiber and the spectrometer were calibrated with a calibration lamp (LH-100FUV) of Gigahertz Optik GmbH (Germany). To guarantee the same angle of incidence in intraocular and reference measurements, an optical bench was set up.

To measure the intraocular irradiance $E_{\text {intra }}$, the samples were placed in the optical bench and fixed posteriorly to the macula using an incision lance. The lance was removed and only the trocar remained. With the fixation in the optical bench, the trocar was reproducibly positioned in the eye. A $23 \mathrm{G}$ trocar was positioned in the macular region. The sensor was 


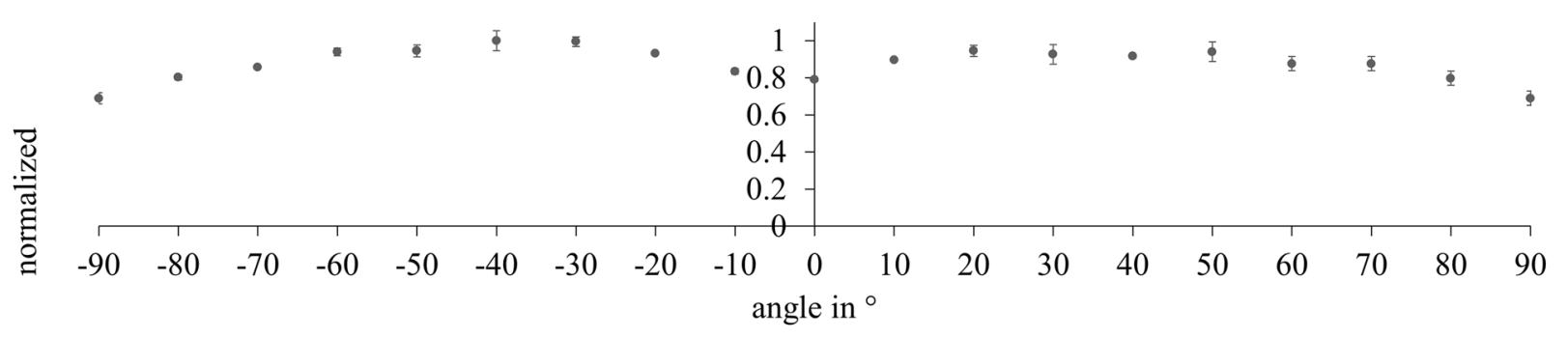

Fig. 2 Normalized sensitivity of the detection fiber with diffusor tip (Thorlabs, CFDSB20, NA $=0.37$ )

inserted in this trocar, protruding $1 \mathrm{~mm}$ from the trocar. In this setting, the total distance from the sensor tip to the retinal surface was $2 \mathrm{~mm}$. A second $23 \mathrm{G}$ trocar was fixed to the optical bench to guide the sensor fiber and to adjust the angle of the fiber tip to the retinal surface.

A second $23 \mathrm{G}$ trocar was placed in the pars plana area and the endoilluminators were inserted through this trocar. The distance to the measuring fiber was defined by the distance to the guide trocar (Fig. 3). The distances 2, 4, 6, 8 and $10 \mathrm{~mm}$ from the measuring fiber were adjusted to record the course of the irradiance with increasing distance to the retina. The second purpose for the guiding trocar was to define the distance between the emitter and detector tip (Fig. 3). The reference irradiance $E_{\text {ref }}$ measurements were acquired in $0.9 \% \mathrm{NaCl}$ solution.

To calculate a theoretical radiant exposure $H_{\mathrm{e}}$ for comparison of the results, a hypothetical exposure time of $1 \mathrm{~h}$ was selected. This is the

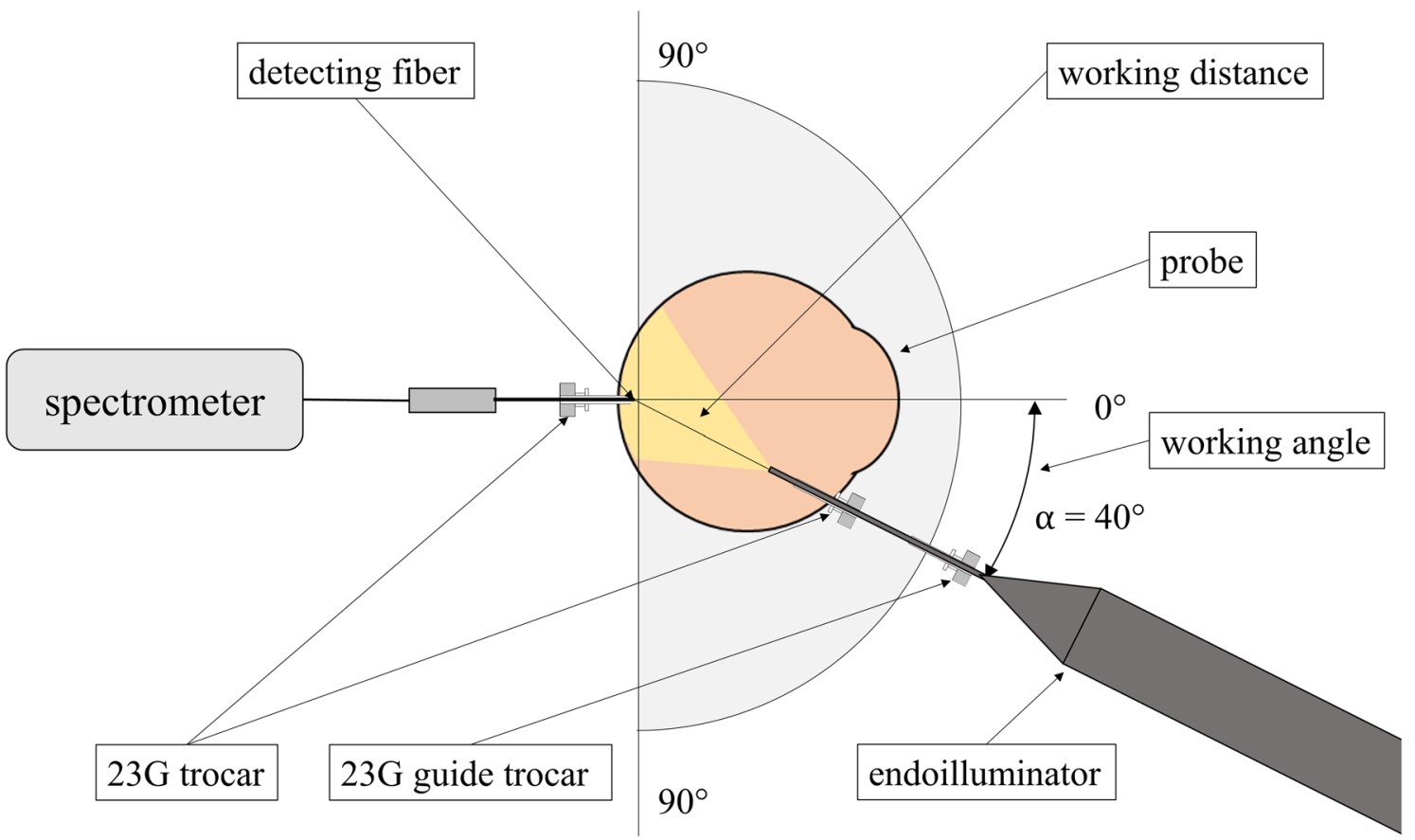

Fig. 3 Measurement setup for intraocular and reference measurement of the irradiance $E$. The irradiance was measured by an optical fiber with a diffusor tip (Thorlabs, CFDSB20, $\mathrm{NA}=0.37$ ). The diffusor tip enables the detection of irradiation with an angle of incidence more than $180^{\circ}$. The angular-dependent sensitivity is always $70 \%$ for $\pm 90^{\circ}$. The reference irradiance measurement is performed without a probe in $0.9 \% \mathrm{NaCl}$ solution and $40^{\circ}$ to the $0^{\circ}$ axis 
time of the standard to reach a classification in group 1 for illumination systems [10].

\section{Statistical Analysis}

The mean values and the standard deviations were calculated for the defined distances to the detection tip. A correlation was determined for each measuring series. To determine the error of the ratio $Q_{\text {intra/ref }}$ between intraocular and reference irradiance, the error propagation was calculated.

In order to investigate and test the suspected effects, the data was examined for statistical significance with IBM SPSS Statistics (version 24). The surveys were examined for normal distribution, to check the requirements for $t$ tests [28] and the Welch test [29]. To examine the difference between intraocular and reference irradiance, the Welch test was selected. The Welch test was also adduced to determine the difference in intraocular irradiance between eyes with blue and brown irises. The paired $t$ test was used to examine the irradiances in the same samples with different endoilluminators. Finally, the Cohen coefficients $d$ and $r$ for effect size [30] of differences between the mean values were calculated for each test.

\section{RESULTS}

\section{Hand-held 23G Spotlight Endoilluminator (AH)}

The results of the intraocular measurements $\left(E_{\text {intra }}\right)$ with the $\mathrm{AH}$ endoilluminator were significantly higher $(\alpha=0.05)$ than the results of the reference measurements $\left(E_{\mathrm{ref}}\right)$ for all 5 measured distances to the retina from 2 to $10 \mathrm{~mm}$ in the porcine eyes (Table 1, Fig. 4a). Comparison of intraocular and reference irradiances using the Welch test showed $t$ values between 5.84 and 8.48 and, consequently, all $p$ values were $<0.001$.

The investigations of the effect size of the differences of the mean values according to Cohen revealed very high values of $d$ and $r$. The $d$ value, based on the $t$ value and the degrees of freedom $t(d f)$ were $3.17<d<4.45(0.85<r<0.91)$.
The resulting ratios $Q_{\text {intra/ref }}$ revealed the values of $1.54 \pm 0.27$ for $2 \mathrm{~mm}, 1.46 \pm 0.29$ for $4 \mathrm{~mm}, 1.42 \pm 0.23$ for $6 \mathrm{~mm}, 1.39 \pm 0.27$ for 8 $\mathrm{mm}$ and $1.42 \pm 0.28$ for $10 \mathrm{~mm}$ (Fig. $5 \mathrm{a}$ ).

\section{Hand-held 23G Wide-field Endoilluminator (GH)}

The results of intraocular irradiance $E_{\text {intra }}$ with the wide-angle probe $(\mathrm{GH})$ were also significantly higher $(\alpha=0.05)$ in all five positions than reference irradiance $E_{\text {ref }}$ (Table 1, Fig. $4 b$ ). The resulting $t$ values were between 7.85 and 4.05. The $p$ values were $<0.002$ (Table 1 ).

The effect size index $d$ with the wide-angle probe $(\mathrm{GH})$ results in a very high effect with $2.55<d<4.70(0.79<r<0.92)$, as presented in Table 1.

\section{Comparison of Spotlight and Wide-field Illumination}

The differences between the two endoilluminators (AH and $\mathrm{GH}$ ) using the same light source $(\alpha=0.05)$ were also significant at distances from 2 to $10 \mathrm{~mm}$ from the diffusor tip or 4 to $12 \mathrm{~mm}$ from the retina (Table 2).

\section{Comparison of Blue and Brown Irises}

Between eyes of different pigmentation, no significant difference of intraocular irradiance could be detected. The examination whether the intraocular irradiance differs in eyes with different iris colorations and thus different pigmentations revealed no significant differences.

All $p$ values for $\mathrm{AH}$ and $\mathrm{GH}$ were higher than 0.150. According to Cohen, effect sizes were calculated $(0.2<d<1.0)$, but all corresponding values for $r$ were below 0.5 .

\section{Radiant Exposure $H_{\mathrm{e}}$ of One-Hour Exposure Time}

The results of the intraocular and reference irradiance were selected to calculate the radiant exposure for every position. The resulting 
Table 1 Results of the spotlight endoilluminator from Alcon (AH) and of the wide-field endoilluminator from Geuder $(\mathrm{GH})$

\begin{tabular}{|c|c|c|c|c|c|c|c|c|c|c|c|}
\hline \multicolumn{2}{|c|}{ Endoilluminator type } & \multicolumn{5}{|l|}{ AH } & \multicolumn{5}{|l|}{ GH } \\
\hline $\begin{array}{l}\text { Distance to the } \\
\text { diffusor tip }\end{array}$ & [d] in $\mathbf{m m}$ & 2 & 4 & 6 & 8 & 10 & 2 & 4 & 6 & 8 & 10 \\
\hline$E_{\text {intra }}$ & $\begin{array}{l}{\left[E_{\text {intra }}\right] \text { in }} \\
\mathrm{mW} / \mathrm{cm}^{2}\end{array}$ & 106.87 & 37.02 & 17.64 & 10.59 & 7.24 & 30.26 & 13.69 & 7.59 & 4.97 & 3.51 \\
\hline SD & $\begin{array}{l}{\left[E_{\text {intra }}\right] \text { in }} \\
\mathrm{mW} / \mathrm{cm}^{2}\end{array}$ & 15.88 & 6.49 & 2.45 & 1.88 & 1.13 & 4.54 & 2.06 & 1.21 & 0.78 & 0.58 \\
\hline MSE & $\begin{array}{l}{\left[E_{\text {intra }}\right] \text { in }} \\
\mathrm{mW} / \mathrm{cm}^{2}\end{array}$ & 4.24 & 1.74 & 0.66 & 0.50 & 0.30 & 1.21 & 0.55 & 0.32 & 0.21 & 0.15 \\
\hline$E_{\text {ref }}$ & $\begin{array}{l}{\left[E_{\mathrm{ref}}\right] \text { in }} \\
\quad \mathrm{mW} / \mathrm{cm}^{2}\end{array}$ & 69.54 & 25.33 & 12.46 & 7.62 & 5.09 & 18.59 & 9.85 & 5.71 & 3.90 & 2.68 \\
\hline SD & $\begin{array}{l}{\left[E_{\mathrm{ref}}\right] \text { in }} \\
\mathrm{mW} / \mathrm{cm}^{2}\end{array}$ & 2.03 & 0.57 & 0.29 & 0.13 & 0.22 & 1.49 & 0.52 & 0.43 & 0.28 & 0.11 \\
\hline MSE & $\begin{array}{l}{\left[E_{\mathrm{ref}}\right] \text { in }} \\
\mathrm{mW} / \mathrm{cm}^{2}\end{array}$ & 1.17 & 0.33 & 0.17 & 0.08 & 0.12 & 0.86 & 0.30 & 0.25 & 0.16 & 0.06 \\
\hline$Q_{\text {intra/ref }}$ & - & 1.54 & 1.46 & 1.42 & 1.39 & 1.42 & 1.63 & 1.39 & 1.33 & 1.27 & 1.31 \\
\hline$\Delta Q$ & - & 0.27 & 0.29 & 0.23 & 0.27 & 0.28 & 0.37 & 0.28 & 0.31 & 0.29 & 0.27 \\
\hline$t(d f)$ & - & 14.51 & 13.84 & 14.38 & 13.58 & 14.98 & 11.15 & 13.84 & 10.09 & 10.01 & 14.97 \\
\hline$t$ value & - & 8.48 & 6.62 & 7.65 & 5.84 & 6.61 & 7.85 & 6.12 & 4.61 & 4.05 & 4.93 \\
\hline$p$ value & - & 0.001 & 0.001 & 0.001 & 0.001 & 0.001 & 0.001 & 0.001 & 0.001 & 0.002 & 0.001 \\
\hline$d$ & - & 4.45 & 3.56 & 4.03 & 3.17 & 3.42 & 4.70 & 3.29 & 2.90 & 2.56 & 2.55 \\
\hline$r$ & - & 0.91 & 0.87 & 0.90 & 0.85 & 0.86 & 0.92 & 0.85 & 0.82 & 0.79 & 0.79 \\
\hline
\end{tabular}

The table illustrates the intraocular irradiance $E_{\text {intra }}$ and the reference irradiance $E_{\text {ref }}$ at distances of 2, 4, 6,8 and $10 \mathrm{~mm}$ from the diffusor tip. $Q_{\text {intra/ref }}$ represents the ratio between the intraocular irradiance $E_{\text {intra }}$ and the reference irradiance $E_{\text {ref. }}$. The values $t, p$ and the degrees of freedom $t(d f)$ are selected to calculate the values $d$ and $r$ according to Cohen [30]. $S D$ standard deviation, $M S E$ mean squared error

intraocular and reference radiant exposures are illustrated in Table 3. Thus, the values were calculated by the irradiance $E$, and the intraocular and reference radiant exposure resulted in the same ratio as the irradiance.

\section{DISCUSSION}

The comparison of the intraocular irradiance $E_{\text {intra }}$ and the reference irradiance $E_{\text {ref }}$ resulted in significantly higher values for the intraocular irradiance at distances of 2, 4, 6, 8 and $10 \mathrm{~mm}$ to the diffusor tip ( $+2 \mathrm{~mm}$ to the retina).

The resulting radiant exposures always revealed higher results than the safe guide of $10 \mathrm{~J} / \mathrm{cm}^{2}$ for intraocular illumination (Table 3 ) [10], except for one measured value $\left(\mathrm{GH} H_{\text {ref: }}\right.$ : $10 \mathrm{~mm}$ ). In all these positions, damage of the retinal tissue would be possible [23] for a 1-h application.

Our results support the hypothesis that the partially spherical geometry of the eye increases the radiation on the surface compared to a reference setting. Pigmentation of the eyes had no 


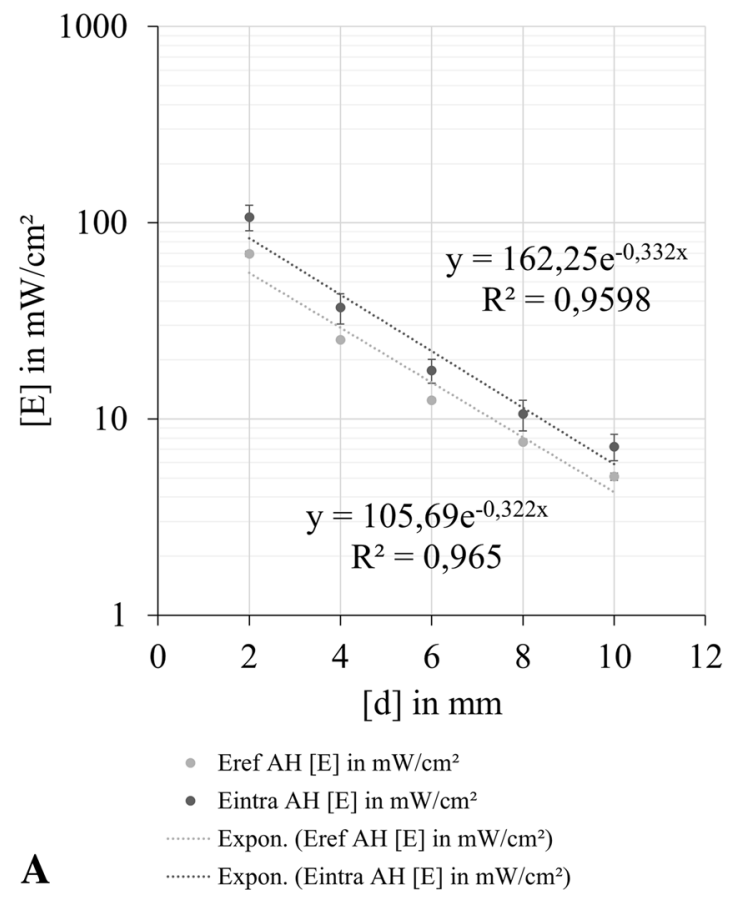

Fig. 4 Intraocular irradiance $E_{\text {intra }}$ and reference irradiance $E_{\text {ref. a Describes the results of the spotlight }}$ endoilluminator from Alcon (AH). The intraocular measurement results are higher compared to the reference

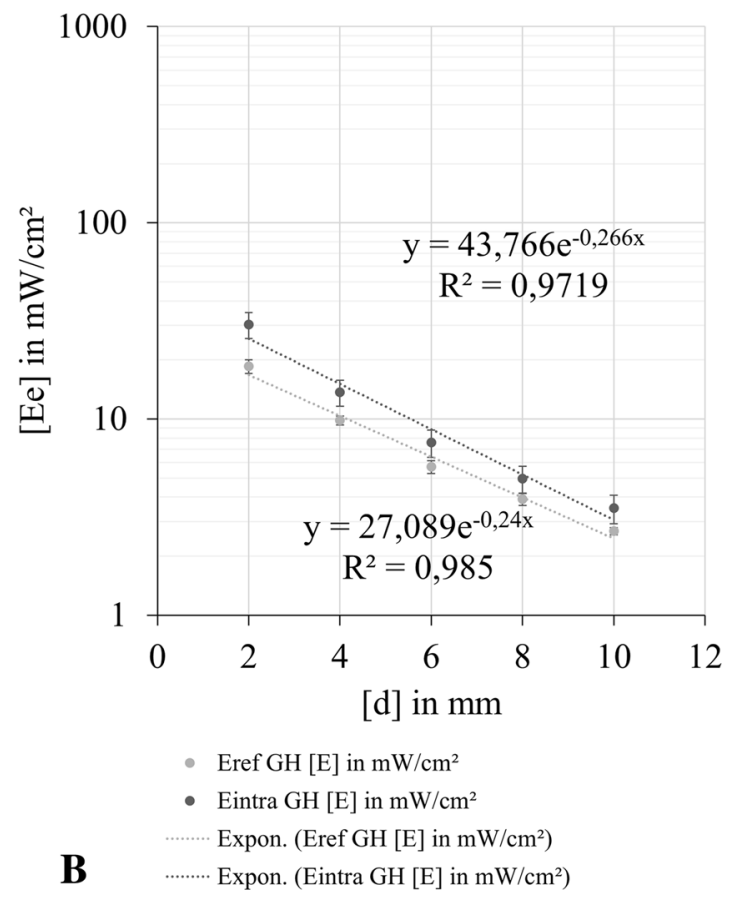

ones. b Illustrates the results with the wide-angle endoilluminator from Geuder $(\mathrm{GH})$. The intraocular measurement results are higher than the reference approach

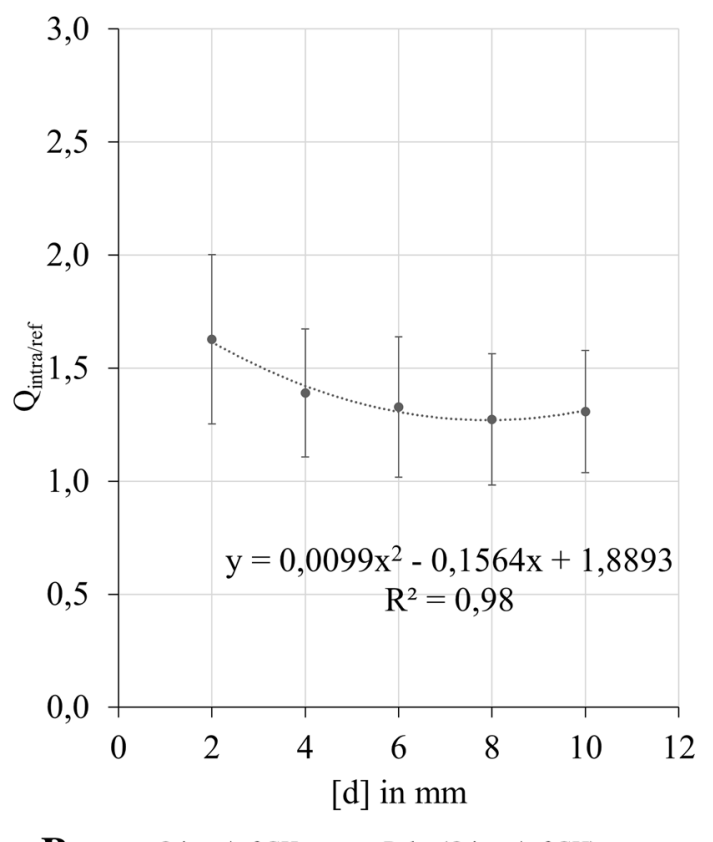

B - $\mathrm{Q}$ intra/ref GH ……. Poly. (Q intra/ref GH)

Fig. 5 Ratios of intraocular and reference irradiance depending on the distance to the retina. a Plots the results of the spotlight endoilluminator from Alcon (AH) and $\mathbf{b}$ the results of the wide-angle endoilluminator from Geuder (GH) 
Table 2 Results of the comparison between the illumination with $\mathrm{AH}$ and $\mathrm{GH}$ endoilluminators for the same light source in the same eyes

\begin{tabular}{llllll}
\hline $\mathbf{m m}$ & $\boldsymbol{t}(\boldsymbol{d} \boldsymbol{f})$ & $\boldsymbol{t}$ value & $\boldsymbol{p}$ value & $\mathbf{d z}$ & $\boldsymbol{r}$ \\
\hline 2 & 13 & 16.02 & 0.001 & 4.28 & 0.98 \\
4 & 13 & 11.49 & 0.001 & 3.07 & 0.95 \\
6 & 13 & 13.50 & 0.001 & 3.61 & 0.97 \\
8 & 13 & 9.74 & 0.001 & 2.60 & 0.94 \\
10 & 13 & 10.06 & 0.001 & 2.69 & 0.94 \\
\hline
\end{tabular}

The comparison was calculated with a paired $t$ test with SPSS and the effect size index $d$ of Cohen [30]

significant influence on these results, because the pigment is located in the RPE cells and therefore behind the retina. Therefore, the reason for this increased radiation should be light surface interaction. This measurable effect is presumably a complex interplay between reflection, transflection and scattering. We also demonstrated that different radiation characteristics of endoilluminators resulted in different radiation intensity onto the retina. A spotlight generated higher local irradiance compared to a wide-angle light.

The radiant exposures leading to irreversible damage of the retina are usually measured in vivo [18-21, 23], but illumination systems are characterized in reference settings. Therefore, the specified guide values $[10,24]$ could be assumed to be too low.

Surgeons must be careful not to exceed the maximum recommended exposure time. Our measurements suggest that even this time does not mean absolute safety for the retina, as there is a higher radiation exposure in the eye than in the measurement setup for the recommendations. In addition, intraoperative situations occur in which the light source is brought closer to the retina and, in consequence, the radiation exposure increases exponentially.

In fact, the use of the light sources in duration and distance during the operation depends on the intraoperative necessities. For the calculation of the radiation exposure in the eye, many of the parameters are variable.

Table 3 Radiant exposure for intraocular and reference irradiance by an exposure time of $1 \mathrm{~h}$ with the spotlight endoilluminator from Alcon (AH) and of the wide-field endoilluminator from Geuder $(\mathrm{GH})$

\begin{tabular}{|c|c|c|c|c|c|c|c|c|c|c|c|}
\hline \multicolumn{2}{|c|}{ Endoilluminator type } & \multicolumn{5}{|l|}{ AH } & \multicolumn{5}{|l|}{ GH } \\
\hline $\begin{array}{l}\text { Distance to the } \\
\text { diffusor tip }\end{array}$ & [d] in $\mathbf{m m}$ & 2 & 4 & 6 & 8 & 10 & 2 & 4 & 6 & 8 & 10 \\
\hline$H_{\text {intra }}$ & $\begin{array}{c}{\left[H_{\text {intra }}\right] \text { in }} \\
\mathrm{J} / \mathrm{cm}^{2}\end{array}$ & 384.72 & 133.29 & 63.52 & 38.13 & 26.07 & 108.94 & 49.29 & 27.31 & 17.88 & 12.64 \\
\hline SD & $\begin{array}{c}{\left[H_{\text {intra }}\right] \text { in }} \\
\mathrm{J} / \mathrm{cm}^{2}\end{array}$ & 57.18 & 23.38 & 8.83 & 6.76 & 4.06 & 16.35 & 7.41 & 4.34 & 2.81 & 2.09 \\
\hline MSE & $\begin{array}{c}{\left[H_{\text {intra }}\right] \text { in }} \\
\mathrm{J} / \mathrm{cm}^{2}\end{array}$ & 15.28 & 6.25 & 2.36 & 1.81 & 1.09 & 4.37 & 1.98 & 1.16 & 0.75 & 0.56 \\
\hline$H_{\text {ref }}$ & $\begin{array}{c}{\left[H_{\mathrm{ref}}\right] \text { in }} \\
\mathrm{J} / \mathrm{cm}^{2}\end{array}$ & 250.36 & 91.20 & 44.87 & 27.45 & 18.31 & 66.91 & 35.45 & 20.56 & 14.04 & 9.66 \\
\hline SD & $\begin{array}{c}{\left[H_{\mathrm{ref}}\right] \text { in }} \\
\mathrm{J} / \mathrm{cm}^{2}\end{array}$ & 7.30 & 2.05 & 1.06 & 0.48 & 0.78 & 5.35 & 1.89 & 1.54 & 1.00 & 0.40 \\
\hline MSE & $\begin{array}{c}{\left[H_{\mathrm{ref}}\right] \text { in }} \\
\mathrm{J} / \mathrm{cm}^{2}\end{array}$ & 4.22 & 1.18 & 0.61 & 0.28 & 0.45 & 3.09 & 1.09 & 0.89 & 0.58 & 0.23 \\
\hline
\end{tabular}

The table also includes intraocular radiant exposure $H_{\text {intra }}$ and the reference radiant exposure $H_{\text {ref }}$ at distances of 2, 4, 6, 8 and $10 \mathrm{~mm}$ from the diffusor tip. SD standard deviation, MSE mean squared error 
The difficulty therefore lies in measuring the actual intraoperative radiation exposure of the retina. This depends on the light intensity (radiant power in $W$ ), the distance of the light source from the retina ( $d$ in $\mathrm{mm}$ ), the exposure time ( $t$ in $s$ ), the angle of incidence, the light spectrum and, as described in this paper, the light surface interaction on the retinal surface (indirect light exposure). The determining factor is the distance between the illuminating tip and the retina. And the irradiance is squaredependent on the distance. So, halving the distance from the retina results in a quadrupling of the irradiance.

With a defined distance and defined light intensity, the irradiance $\left(E\right.$ in $\left.\mathrm{W} / \mathrm{cm}^{2}\right)$ can be calculated for a defined area $\left(\mathrm{cm}^{2}\right)$. In the standards for intraocular illumination [10, 24], the distance of $15 \mathrm{~mm}$ is estimated for endoilluminators. In this condition, a safe exposure time can be calculated.

In real life, the distance of the light source follows the needs of the operation. For a chandelier light, the value of $15 \mathrm{~mm}$ is probably representative, whereas for a spotlight and a wide-angle light, $15 \mathrm{~mm}$ is probably too high.

\section{CONCLUSION}

Our results show for all situations in the eye that the exposure to radiation on the retina is 1.5 times higher than in the reference setting. Therefore, the anatomy of the eye should be considered when calculating the maximum exposure to endoilluminators.

\section{ACKNOWLEDGEMENTS}

Funding. This work was financially supported by the German Federal Ministry of Economics and Technology within the ZIM joint project "Safe Light" (Grant number ZF4137902AK9). No funding was received for the publication of this article.

Authorship. All named authors meet the International Committee of Medical Journal
Editors (ICMJE) criteria for authorship for this article, take responsibility for the integrity of the work as a whole, and have given their approval for this version to be published.

Disclosures. Philipp S. Koelbl is financed by the ZIM project "Safelight". Martin Hessling, Christian Lingenfelder and Sebastian Kupferschmid have nothing to disclose.

Compliance with Ethics Guidelines. All institutional and national guidelines for the care and use of laboratory animals were followed.

Open Access. This article is distributed under the terms of the Creative Commons Attribution-NonCommercial 4.0 International License (http://creativecommons.org/licenses/ by-nc/4.0/), which permits any noncommercial use, distribution, and reproduction in any medium, provided you give appropriate credit to the original author(s) and the source, provide a link to the Creative Commons license, and indicate if changes were made.

\section{REFERENCES}

1. Fuller D, Machemer R, Knighton RW. Retinal damage produced by intraocular fiber optic light. Am J Ophthalmol. 1978;85:519-37.

2. Ham WT, Mueller HA, Sliney D. Retinal sensitivity to damage from short wavelength light. Nature. 1976;260:153-5.

3. Ham WT, William T, Ruffolo JJ, Mueller HA, Guerry D. The nature of retinal radiation damage: dependence on wavelength, power level and exposure time. Vis Res. 1980;20:1105-11.

4. Ham WT, Ruffolo JJ, Mueller HA, Clarke Am, Moon ME. Histologic analysis of photochemical lesions produced in rhesus retina by short-wave-length light. Investig Ophthalmol Vis Sci. 1978;17:1029-35.

5. Irvine AR, Wood I, Morris BW. Retinal damage from the illumination of the operating microscope: an experimental study in pseudophakic monkeys. Arch Ophthalmol. 1984;102:1358-65. 
6. Johnson DD, O'steen WK, Duncan TE. Photicallyinduced retinal damage in diabetic rats. Curr Eye Res. 2009;5:1-7.

7. Lanum J. The damaging effects of light on the retina. Empirical findings, theoretical and practical implications. Surv Ophthalmol. 1978;22:221-49.

8. Lawwill T. Effects of prolonged exposure of rabbit retina to low-intensity light. Investig Ophthalmol Vis Sci. 1973;12:45-51.

9. Lawwill T, Crockett S, Currier G. Retinal damage secondary to chronic light exposure. Doc Ophthalmol. 1977;44:379-402.

10. DIN Deutsches Institut für Normung e. V. Ophthalmic instruments-Fundamental requirements and test methods-Part 2: Light hazard protection (ISO/DIS 15004-2:2014); German version prEN ISO 15004-2:2014. 10772 Berlin: Beuth Verlag GmbH; 2014 April 2014.

11. Huenig S. Optimierter Lichtschutz der Augen: eine dringende Aufgabe und ihre Lösung. Z prakt Augenheilkd. 2009;29:111-6.

12. Mellerio J. Light effects on the retina. Princ Pract Ophthalmol. 1994;116:1-23.

13. Udovičić L, Mainusch F, Janßen M, Nowack D, Ott G. Photobiologische Sicherheit von Licht emittierenden Dioden (LED). Dortmund: Bundesanstalt für Arbeitsschutz und Arbeitssicherheit; 2013.

14. Różanowska M, Sarna T. Light-induced damage to the retina: role of rhodopsin chromophore revisited. Photochem Photobiol. 2005;81:1305-30.

15. Koch FHJ, Schmidt HP, Mönks T, Blumenröder SH, Haller A, Steinmetz RL. The retinal irradiance and spectral properties of the multiport illumination system for vitreous surgery. Am J Ophthalmol. 1993;116:489-96.

16. Boulton M, Różanowska M, Różanowski B. Retinal photodamage. J Photochem Photobiol B. 2001;64:144-61.

17. Hope-Ross MW, Mahon GJ, Gardiner TA, Archer DB. Ultrastructural findings in solar retinopathy. Eye. 1993; 7:29.

18. Friedman E. The retinal pigment epithelium. Arch Ophthalmol. 1968;80:265.
19. Jaadane I, Boulenguez P, Chahory S, Carré S, Savoldelli M, Jonet L, et al. Retinal damage induced by commercial light emitting diodes (LEDs). Free Radic Biol Med. 2015;84:373-84.

20. Krigel A, Berdugo M, Picard E, Levy-Boukris R, Jaadane I, Jonet L, et al. Light-induced retinal damage using different light sources, protocols and rat strains reveals LED phototoxicity. Neuroscience. 2016;339:296-307.

21. Shang Y-M, Wang G-S, Sliney D, Yang C-H, Lee L-L. Light-emitting-diode induced retinal damage and its wavelength dependency in vivo. Int J Ophthalmol. 2017;10:191-202.

22. Ach T, Höh AE, Amberger R, Dithmar S. Lichtexposition bei vitreoretinaler Chirurgie. Der Ophthalmologe. 2008;105:905-10.

23. Ueda $T$, Nakanishi-Ueda $T$, Yasuhara $H$, Koide R, Dawson WW. Eye damage control by reduced blue illumination. Exp Eye Res. 2009;89:863-8.

24. DIN Deutsches Institut für Normung e. V. Normenausschuss Feinmechanik und Optik (NAFuO) im DIN. Ophthalmische Instrumente-Endoilluminatoren-Grundlegende Anforderungen und Prüfverfahren in Bezug auf die optische Strahlungssicherheit (ISO 15752:2010) Deutsche Fassung EN ISO 15752:2010. 10772 Berlin: Beuth Verlag GmbH; 20102010.

25. Naumann GOH. Pathologie des Auges 1. 2., völlig neubearb. und erg Aufl. Berlin: Springer; 1997.

26. Naumann GOH. Pathologie des Auges 2. 2., völlig neubearb. und erg. Aufl. Berlin: Springer; 1997.

27. Sanchez I, Martin R, Ussa F, Fernandez-Bueno I. The parameters of the porcine eyeball. Graefe's Arch Clin Exp Ophthalmol. 2011;249:475-82.

28. Student. The probable error of a mean. Biometrika. $1908 ; 6: 1-25$.

29. Welch BL. The generalization of 'student's' problem when several different population variances are involved. Biometrika. 1947;34:28-35.

30. Cohen J. Statistical power analysis for the behavioral sciences. 2nd ed. Hillsdale: Lawrence Erlbaum Associates; 1988. 